\title{
STUDI KANDUNGAN BAKTERI Salmonella sp PADA SATE KAMBING YANG DIJUAL DI KECAMATAN BUMIAYU KABUPATEN BREBES TAHUN 2014
}

\author{
Elendea Windi Arfila*), Priyo Santoso, SKM, M.Kes
}

\begin{abstract}
Salmonellosis caused gastroenteristis (acute indigestion), the cause is Salmonella choleraesuis dan Salmonella enteriditis. Salmonellosis occur after an incubation time of 5-72 hours after eating food containing Salmonella. Symptoms are abdominal pain, diarrhea, nausea and headache. The purpose of this study was to determine the presence or absence of Salmonella in goat satay sold in District of Bumiayu Subprovince of Brebes Year 2014.

Research methodology that is used is descriptive, data that have been collected will be compared with the exist standard.

Based on the results obtained, hygiene sanitation management satay at 6 places ranging from the selection of foodstuffs, foodstuff storage, food processing, transporting and serving food that the food was good with a score of $88.05 \%$. Based on the examination of 6 samples in the laboratory goat satay can be seen that 4 samples did not meet the standards because of the positive Salmonella while 2 negative samples that meet the standards set are negative (zero).

The conclusion of this research is the sanitation management of satay in six place with a score that is already a good $88.05 \%$, and 6 samples of goat satay can be seen that 4 samples did not meet the standards because of the positive Salmonella while the 2 sample negative Salmonella so as to meet the standards that have been determined under National Agency for Drugs and Food Control Number.HK.00.06.1.52.4011, 2009 about the determining contamination maximum limination of microba and chemistry on the food that is negative (zero). Suggestions can be given that the goat satay be consumed should be completely cooked and when preparing food should refer to aspects of food sanitation hygiene to prevent contamination.
\end{abstract}

$\begin{array}{ll}\text { Reading List } & : 22(1987-2014) \\ \text { Key word } & : \text { Salmonella, Goat Satay } \\ \text { Classification } & :-\end{array}$

*) Alumni Mahasiswa Jurusan Kesehatan Lingkungan Purwokerto

${ }^{* *}$ ) Dosen Jurusan Kesehatan Lingkungan Purwokerto

\section{PENDAhULUAN}

\section{A. Latar Belakang}

Tujuan pembangunan kesehatan menuju Indonesia sehat 2025 adalah meningkatkan kesadaran, kemauan, dan kemampuan hidup sehat bagi setiap orang agar peningkatan derajat kesehatan masyarakat yang setinggi-tingginya dapat terwujud melalui terciptanya masyarakat, bangsa dan negara Indonesia yang ditandai oleh penduduknya yang hidup dengan perilaku dan dalam lingkungan sehat, memiliki kemampuan untuk menjangkau pelayanan kesehatan yang setinggi-tingginya di seluruh wilayah Republik Indonesia. (RPJK (2005-2025),h.35)

Makanan dan minuman seringkali menjadi penyebab timbulnya berbagai macam penyakit. Makanan atau minuman yang tercemar akan menjadi media yang baik bagi pertumbuhan mikroorganisme (bakteri). Bakteri yang sering dijumpai pada makanan dan minuman tercemar salah satunya adalah Salmonella sp. Gejala-gejala yang muncul akibat terinfeksi bakteri tersebut mulai dari mual, muntah, sakit tenggorokan, kram perut, diare, alergi dan infeksi secara umum (Retno widyanti,dkk.2002).

$\mathrm{Di}$ Indonesia masih sering terjadi keracunan sate seperti kasus yang terjadi pada tanggal 13 Desember 2012 di desa Lubuk Godang Kecamatan Koto Balingka Kabupaten Pasaman Barat, Sumatera Barat, ada 40 korban keracunan sate yang dirawat di Puskesmas Ujung Gading. Keracunan mulai dari kalangan dewasa dan anak-anak itu diduga karena memakan sate dari salah satu pedagang sate keliling yang melintas di daerah setempat, semua korban mengalami pusing, mual dan muntah. Setelah pengujian 
sampel, ternyata sate tersebut mengandung bakteri Salmonella

(http://regional.kompas.com/read/2012/12/13/ 08505129/mediasiber.html). Kasus yang sama pada tanggal 3 November 2013 di Ponorogo, Jawa Timur ada 104 orang yang dirawat di Puskesmas Pulung setelah menyantap hidangan sate dan gule kambing pada acara hajatan akikah, korban mengalami pusing, mual dan muntah. (http://m.okezone.com/read/2013/11/03/521/ 891219/korban-keracunan-sate-gule mencapai-104-orang).

Sate kambing menjadi makanan kegemaran bagi sebagian keluarga. Konsumsi sate kambing merupakan salah satu indikasi tingginya kesadaran masyarakat akan kebutuhan protein hewani. Biasanya sate kambing disajikan setengah matang sehingga bakteri dengan mudah menggunakannya sebagai media pertumbuhan. Makanan yang kurang matang pada umumnya merupakan penyebab penyakit Botulism (peracunan makanan yang disebabkan oleh bakteri). Masakan yang kurang matang dapat terjadi bila memasak daging berukuran besar karena ukurannya itu menambah masalah penetrasi panas yang cukup. Tanpa penggunaan suhu yang cukup tinggi dan cukup lama, mikroorganisme tidak terbunuh atau racun yang tahan panas (Botulinum) tidak termusnahkan (Koes Irianto, 2006, h. 90). Pedagang sate kambing di Kecamatan Bumiayu saat ini ada 6 pedagang yang menetap. Berdasarkan survey pendahuluan, 5 dari 9 konsumen yang telah diwawancarai menghendaki sate kambing setengah matang karena menurut mereka sate yang setengah matang mempunyai cita rasa yang berbeda. Hal tersebut dikhawatirkan bakteri Salmonella masih hidup pada sate kambing yang setengah matang dan kemungkinan besar konsumen yang memakan sate tersebut bisa keracunan. Salmonellosis menyebabkan gastroenteristis (gangguan saluran pencernaan akut), penyebabnya adalah Salmonella choleraesuis dan Salmonella enteriditis. Salmonellosis terjadi setelah waktu inkubasi 5-72 jam setelah memakan makanan yang mengandung Salmonella. Gejala yang ditimbulkan adalah sakit perut, diare, mualmual, dan sakit kepala (Arisman, 2009, h.76)

Berdasarkan latar belakang di atas penulis merasa tertarik untuk melakukan penelitian dengan judul "Studi Kandungan Bakteri Salmonella sp Pada Sate Kambing

\section{Yang Dijual Di Kecamatan Bumiayu} Kabupaten Brebes Tahun 2014".

\section{B. Perumusan Masalah}

Apakah ada kandungan bakteri Salmonella sp pada sate kambing yang dijual di Kecamatan Bumiayu Kabupaten Brebes tahun 2014?

\section{Tujuan}

1. Tujuan Umum

Mengetahui kandungan bakteri Salmonella sp pada sate kambing yang dijual di Kecamatan Bumiayu Kabupaten Brebes tahun 2014.

2. Tujuan Khusus

a. Mendeskripsikan cara pemilihan bahan makanan.

b. Mendeskripsikan cara penyimpanan daging kambing segar sebelum diolah.

c. Mendeskripsikan cara pengolahan daging kambing segar menjadi sate kambing

d. Mendeskripsikan cara pengangkutan sate kambing.

e. Mendeskripsikan cara penyimpanan sate kambing.

f. Mendeskripsikan cara penyajian sate kambing.

g. Mendeskripsikan ada tidaknya bakteri Salmonella sp pada sate kambing yang dijual di Kecamatan Bumiayu Kabupaten Brebes tahun 2014.

\section{Manfaat}

1. Bagi Masyarakat

Memberikan informasi dan pengetahuan tentang kualitas sate kambing yang baik, aman dan sehat untuk dikonsumsi masyarakat baik penjual dan pembeli dalam meningkatkan kewaspadaan terhadap bahaya bakteri Salmonella sp.

2. Bagi Pemerintah

Penelitian ini diharapkan agar pemerintah setempat melakukan pemantauan dan pengawasan terhadap sanitasi tempat penjualan sate kambing sehingga diperoleh peningkatan mutu tempat penjualan yang saniter.

3. Bagi Almamater

Hasil penelitian ini dapat digunakan sebagai acuan peneliti sejenis serta tambahan bahan kepustakaan Poltekkes Kemenkes Semarang Jurusan Kesehatan Lingkungan Purwokerto. 
4. Bagi Peneliti

Memberikan wawasan pengetahuan dan pengalaman kerja lapangan dalam melakukan penelitian kandungan bakteri Salmonella sp pada sate kambing.

\section{METODE PENELITIAN}

\section{A. Kerangka Pikir}

1. Komponen Penyusun

a. Input
1) Penjamah
2) Alat
3) Bahan
4) Tempat pengolahan

b. Proses

1) Pemilihan daging kambing segar

2) Penyimpanan daging kambing

3) Pengolahan daging kambing segar menjadi sate kambing

4) Pengangkutan sate kambing.

5) Penyimpanan sate kambing

6) Penyajiaan sate kambing

c. Output Ada tidaknya kandungan

Salmonella sp pada sate kambing.

2. Gambar Kerangka Pikir

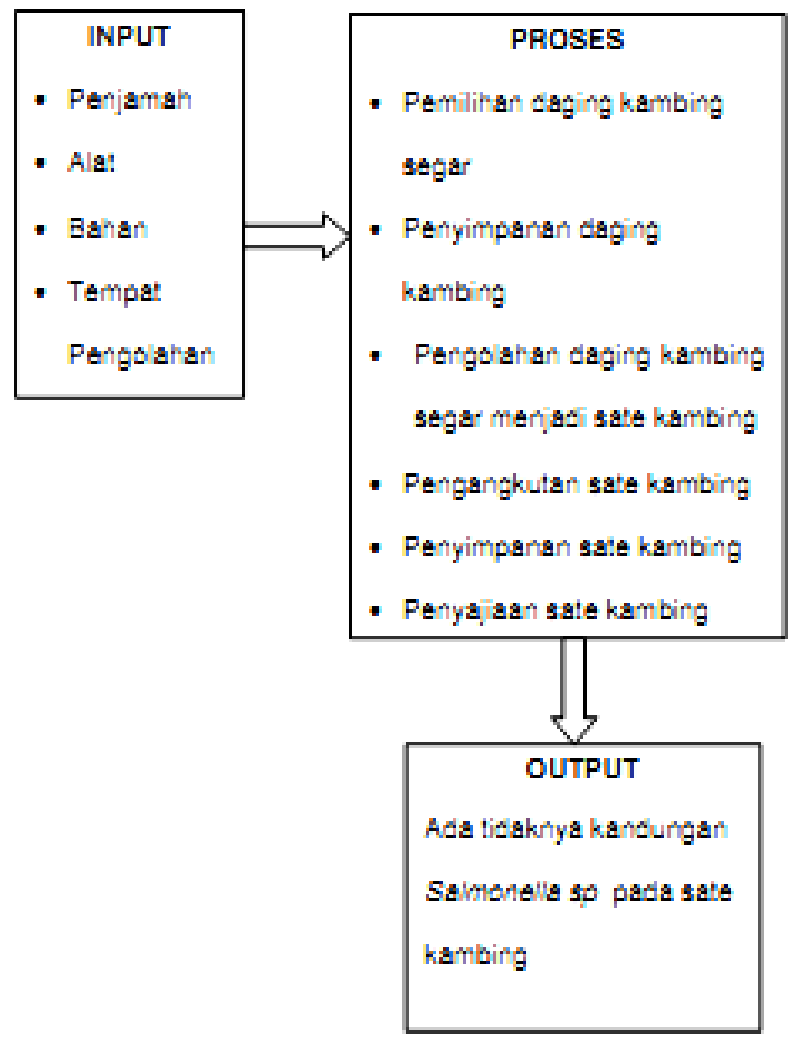

Gambar 3.1

Kerargka Plkir

\section{B. Jenis Penelitian}

Jenis penelitian ini adalah penelitian deskriptif yaitu memberi gambaran tentang ada tidaknya bakteri Salmonella sp pada sate kambing yang dijual di Kecamatan Bumiayu Kabupaten Brebes tahun 2014.

\section{Ruang Lingkup}

1. Waktu Penelitian

a. Tahap Persiapan : Desember 2013Februari 2014

b. Tahap Pelaksanaan: Mei - Juni 2014

c. Tahap Penyelesaian: Juni - Juli 2014 2. Lokasi

Pada penelitian ini penulis mengambil lokasi di Kecamatan Bumiayu untuk analisis sampel mengenai Salmonella dilakukan di Laboratorium Politeknik Kesehatan Semarang Prodi DIII Kesehatan Lingkungan Purwokerto.

3. Materi

Materi penelitian ini adalah kesehatan lingkungan dengan bidang kajian Penyehatan Makanan dan Minuman yang bertujuan untuk mengetahui ada tidaknya Salmonella pada sate kambing yang dijual di Kecamatan Bumiayu.

\section{Subjek Penelitian}

Subyek dalam penelitian ini adalah Salmonella pada sate kambing setengah matang yang dijual oleh pedagang di Kecamatan Bumiayu Kabupaten Brebes. Jumlah sampel yang akan diteliti sebanyak 6 sampel dari produsen yang berbeda.

\section{E. Pengumpulan Data}

1. Jenis Data

a. Data Umum

Data umum merupakan gambaran umum pedagang, nama penjamah, dagangan yang dijual, jumlah pedagang sate kambing yang ada di Kecamatan Bumiayu.

b. Data Khusus

Data khusus yang diperlukan adalah Salmonellapada sate kambing, personal hygiene penjamah dan tempat pengolahan.

2. Sumber Data

Sumber data diperoleh dari data primer yaitu dengan menggunakan checklist dan kuesioner serta uji laboratorium sampel sate kambing yang di jual di Kecamatan Bumiayu Kabupaten Bebes. 
3. Cara Pengumpulan Data

a. Observasi

Melakukan pengamatan dan pencatatan langsung secara nyata di lapangan tentang proses pengolahan sate kambing yang dijual di Kecamatan Bumiayu Kabupaten Brebes.

b. Wawancara

Wawancara dilakukan dengan menggunakan kuesioner pada penjamah sate kambing di Kecamatan Bumiayu Kabupaten Brebes.

c. Pengambilan Sampel

Kegiatan mengambil sampel sate kambing pada pedagang di Kecamatan Bumiayu Kabupaten Brebes.

d. Pemeriksaan

Pemeriksaan Salmonella di laboratorium.

4. Instrument Pengumpulan Data

Dalam penelitian ini instrument yang digunakan adalah :

a. Kuesioner

b. Checklist

c. Alat dan bahan pengambilan sampel dan Pemerikasaan

\section{F. Analisis Data}

Analisis data yang digunakan dalam penelitian ini adalah analisis deskriptif yaitu ada atau tidaknya Salmonella pada sate kambing yang dijual pedagang di Kecamatan Bumiayu, data tersebut ditampilkan dalam bentuk tabel, lalu membandingkan hasil di lapangan dengan Surat Keputusan Dir Jen POM No.HK.00.06.1.52.4011 Tahun 2009 tentang penetapan batas maksimum cemaran mikroba dan kimia dalam makanan adalah negative (nol).

\section{HASIL}

\section{A. Gambaran Umum}

Lokasi penelitian ini dilakukan di Kecamatan Bumiayu Kabupaten Brebes. Kecamatan Bumiayu terletak di sebelah Selatan Ibukota Kabupaten Brebes dengan batas-batas sebagai berikut :

1. Sebelah Utara : Kecamatan Sirampog dan Tonjong

2. Sebelah Selatan: Kecamatan Bantarkawung dan Paguyangan

3. Sebelah Barat: Kecamatan Bantarkawung
4. Sebelah Timur : Kecamatan Paguyangan Jumlah pedagang sate kambing di Kecamatan Bumiayu ada 6 pedagang. Sampel yang diambil adalah sate kambing setengah matang dari semua pedagang. Berikut adalah inisial, kode, pendidikan, tanggal pengambilan sampel dan waktu pengambilan sampel sate kambing :

Tabe 4.1: Inisia, Kode, Pandikikan, Tangag Parganbilan Sampel, Wakt Pargambian sampal Sale Kambirg Di Kasanglan Bumliayu Kabugglent Bubas Tahun 2014

\begin{tabular}{|c|c|c|c|c|c|}
\hline No & Inisial & Kodd & Pendidikan & $\begin{array}{c}\text { Tanggd } \\
\text { Pengambilan }\end{array}$ & $\begin{array}{c}\text { Wektu } \\
\text { Pengambilan }\end{array}$ \\
\hline 1 & NeA & $A$ & SMA & Q Juti 2014 & $08.66 \mathrm{~W} / 8$ \\
\hline 2 & Nr. $B$ & 8 & SMA & E Juti 2014 & OQ.10 W/8 \\
\hline 3 & Mr.C & C & SMA & E Juni 2014 & OQ.15W/8 \\
\hline 4 & Nr.D & 0 & SMA & 9 Juni2014 & OS.20 W/8 \\
\hline 5 & Nr.E & E & SMA & 9 Juni 2014 & O9.55W/8 \\
\hline 6 & Mt:F & $F$ & SMP & 9 Juti 2014 & 10.20 WI \\
\hline
\end{tabular}

Tempat penjualan sate kambing sudah menetap yaitu warung makan sate kambing dan gule. Di sana terdapat meja dan kursi untuk para pembeli yang mau menyantap makanan di tempat. Terdapat pula sarana sanitasi seperti tempat cuci tangan dan kamar mandi di tempat penjualan Mr.B, Mr.C, Mr.D dan Mr.E.

\section{B. Upaya Hygiene Pengolahan Sate Kambing}

Berdasarkan hasil penelitian ini memberikan gambaran tentang keadaan sanitasi pengolahan sate kambing pada pedagang Di Kecamatan Bumiayu Kabupaten Brebes.

1. Penjamah

Dari 6 pedagang sate kambing yang ada di Kecamatan Bumiayu Kabupaten Brebes, penjamah makanan di tempat penjualan Mr.A, Mr.B, Mr.F masing-masing berjumlah 2 penjamah sedangkan di tempat penjualan Mr.C, Mr.D dan Mr.E masing-masing berjumlah 3 penjamah makanan. Semua penjamah makanan tersebut belum mempunyai sertifikat kesehatan. Berikut gambaran personal hygiene pada 6 pedagang sate kambing di Kecamatan Bumiayu yang dilakukan dengan observasi. 
Tabel 4.2. Parsona Hygiente pada B Pecagang Sale Kaming di Kecame:an Bumiay Tahun 2014

\begin{tabular}{|c|c|c|}
\hline & Nams & Personal Hygiene (\%) \\
\hline 1. & $M \cdot A$ & 60) (Clkup Bak) \\
\hline 2. & Mt. 8 & Bo (Bak) \\
\hline 3. & NeC & 60 (Clkup Bak) \\
\hline 4. & Mro & 40 (Kurafg Baik) \\
\hline 5. & MrE & 40. Kurang Raik\} \\
\hline B. & N.F & B0 Bqik \\
\hline
\end{tabular}

Berdasarkan tabel 4.2, personal hygiene yang sudah baik ditemukan pada pedagang Mr.B dan Mr.F yaitu pakaian bersih, kuku pendek, rambut bersih, memakai celemek, tapi tidak menggunakan sarung tangan. Kategori cukup baik ditemukan pada Mr.A dan Mr.C yaitu pakaian bersih, kuku pendek, rambut bersih, tidak memakai celemek dan tidak menggunakan sarung tangan. Kategori kurang baik ditemukan pada Mr.D dan Mr.E yaitu pakaian bersih, kuku panjang, rambut bersih, tidak memakai celemek dan tidak menggunakan sarung tangan saat mengolah makanan.

2. Alat / peralatan

Berdasarkan pengamatan dengan observasi yang telah dilakukan, diperoleh data tentang kondisi sanitasi alat yang digunakan saat pengolahan yang tertera pada tabel 4.3

Trole 4.3. Hygiene Saritasi A at pada Padagang Sale Kambing yarng Diua di Kecanglan Eum ayu Kabupaten Erebes Tanut 2014

\begin{tabular}{|c|c|c|}
\hline No. & Name Pedsgang & Alsi/ Pardialan (\%) \\
\hline 1. & N:A & 100 (Beik) \\
\hline 2. & Nt.8 & 100 , Baik) \\
\hline 3. & NrC & 100 (Baik) \\
\hline 4. & Mt. D & 100 (Bgik) \\
\hline 5. & MrE & 100 (Baik) \\
\hline 6. & Mt. $F$ & 100 (8aik) \\
\hline
\end{tabular}

Berdasarkan tabel di atas dapat dilihat bahwa alat / peralatan pengolahan sate kambing dari semua pedagang masuk dalam kategori baik yaitu bahan anti karat, kedap air, mudah dibeersihkan dan tidak berbau.

3. Bahan

Berdasrakan hasil penelitian menggunakan checklist dan kuesioner, keadaan bahan yang digunakan dalam pengolahan makanan tertera pada tabel 4.4

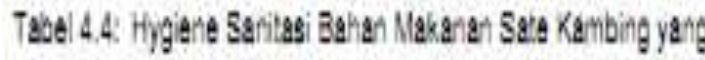

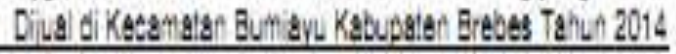

\begin{tabular}{|c|c|c|}
\hline No & Name Padsagang & Bahth Makanen (\%) \\
\hline$\overline{1}$ & W.A & $100(\mathrm{Bg} \mathrm{k})$ \\
\hline 2. & Nr.8 & $100(B a k)$ \\
\hline 3. & $\mathrm{NrC}$ & $100(B a k)$ \\
\hline 4 & Nro & $100(B a k)$ \\
\hline 5. & No.E & 100 (Baik) \\
\hline 8. & Nif & $100(\mathrm{EaK})$ \\
\hline
\end{tabular}

Berdasarkan tabel di atas, semua bahan yang ada pada penjual sate kambing di Kecamatan Bumiayu Kabupaten Brebes termasuk dalam kategori baik yaitu daging kambing beraroma khas, tidak berlendir dan tidak berubah warna.

4. Tempat Pengolahan

Bedasarkan pengamatan dengan observasi yang dilakukan peneliti, kondisi tempat pengolahan sate kambing dapat dilihat pada tabel berikut ini:

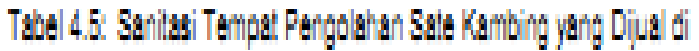

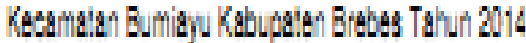

\begin{tabular}{|c|c|c|c|c|c|c|c|}
\hline \multirow{2}{*}{$\begin{array}{l}\text { N Naith } \\
\text { o }\end{array}$} & \multicolumn{7}{|c|}{ 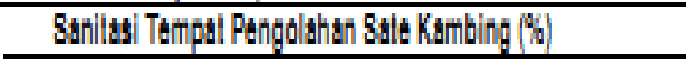 } \\
\hline & 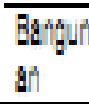 & Lailia & Dinding & Vatt as & $\begin{array}{l}\text { Partat } \\
\text { hyjan }\end{array}$ & Alisp & 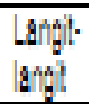 \\
\hline \multirow[t]{2}{*}{ I MA } & 99 & 100 & 100 & 100 & 100 & 100 & 100 \\
\hline & $\begin{array}{l}\text { Titak } \\
\text { Bak }\end{array}$ & [Biki & Bak & (Alk) & {$[\mathrm{ak} k]$} & (ak) & (Bak) \\
\hline \multirow[t]{2}{*}{$2 \mathrm{MB}$} & 98 & 100 & 100 & 100 & 100 & 100 & 100 \\
\hline & $\begin{array}{l}\text { (Tikak } \\
\text { Bakk }\end{array}$ & Bak & (aik & [Bek] & (Bak) & (Bak) & (Bak) \\
\hline \multirow[t]{2}{*}{ I MiC } & 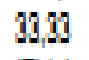 & 100 & 160 & 100 & 100 & 100 & 100 \\
\hline & $\begin{array}{l}\text { (Tidek } \\
\text { Bakk }\end{array}$ & (Bak) & (Bak) & [ak] & [akj] & (Bak) & (Bak) \\
\hline \multirow[t]{2}{*}{$4 \mathrm{MD}$} & 28 & 10 & 10 & 100 & 100 & 10 & 100 \\
\hline & $\begin{array}{l}\text { Tilak } \\
\text { Bakk }\end{array}$ & Baik & Baik & (Bdk) & [akik] & (Bak) & (Bak) \\
\hline \multirow[t]{2}{*}{ 5 ME } & 30 & 10 & 100 & 100 & 100 & 100 & 100 \\
\hline & $\begin{array}{l}\text { [Tikgk } \\
\text { Bakk }\end{array}$ & (Bik) & (Bak) & [edk] & [akj) & (Bak) & (Bak) \\
\hline \multirow[t]{2}{*}{ 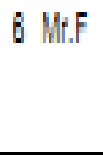 } & $3 \%$ & 10 & 10 & 100 & 100 & 100 & 100 \\
\hline & $\begin{array}{l}\text { Thak } \\
\text { Bak }\end{array}$ & (Bik) & (Gak) & (eik) & (Bak) & (ak) & (ak) \\
\hline
\end{tabular}


Tabel 4.6: Sanitasi Tempa: Pargolahan Sale Kambing yang Diua di

\begin{tabular}{|c|c|c|c|c|c|c|c|}
\hline \multirow{2}{*}{$\begin{array}{l}N \\
0\end{array}$} & \multirow{2}{*}{ Namt } & \multicolumn{6}{|c|}{ Sanilas T Tempat Pengolahan Sate Kambing } \\
\hline & & Pirto & $\begin{array}{l}\text { Ait } \\
\text { Bersih }\end{array}$ & $\begin{array}{l}\text { Pembua } \\
\text { ngan } \\
\text { Limbah }\end{array}$ & Tolia! & $\begin{array}{l}\text { Tempal } \\
\text { Sampan }\end{array}$ & $\begin{array}{l}\text { Tempa: } \\
\text { Cle: } \\
\text { Tanagn }\end{array}$ \\
\hline 1 & Mr.A & $\begin{array}{l}100 \\
\text { (Baik) }\end{array}$ & $\begin{array}{l}100 \\
\text { (Baik) }\end{array}$ & $\begin{array}{l}75 \\
\text { (Cukup } \\
\text { (Baik) }\end{array}$ & $\begin{array}{l}0 \\
\text { (Tisak } \\
\text { Bak) }\end{array}$ & $\begin{array}{l}50 \\
\text { Kurarg } \\
\text { Bak) }\end{array}$ & $\begin{array}{l}\text { D } \\
\text { (Tidak } \\
\text { Eak) }\end{array}$ \\
\hline 2 & Mr. B & $\begin{array}{l}\text { B6,68 } \\
\text { \{Cukup } \\
\text { Bak\}? }\end{array}$ & $\begin{array}{l}100 \\
\langle\text { Bgik) }\end{array}$ & $\begin{array}{l}75 \\
\text { (Cukup } \\
\text { Baik) }\end{array}$ & $\begin{array}{l}\text { BO } \\
\text { (Cukup } \\
\text { Bak) }\end{array}$ & $\begin{array}{l}50 \\
(K \mathrm{krarg} \\
\text { Bak) }\end{array}$ & $\begin{array}{l}100 \\
\text { (Eak) }\end{array}$ \\
\hline 3 & Mr.C & $\begin{array}{l}\text { B6,6B } \\
\text { (Cukup } \\
\text { Bak) }\end{array}$ & $\begin{array}{l}100 \\
\{\text { Baik\} }\end{array}$ & $\begin{array}{l}75 \\
\text { (Cukup } \\
\text { Baik) }\end{array}$ & $\begin{array}{l}\text { Bo } \\
\text { [Baikj) }\end{array}$ & $\begin{array}{l}50 \\
\text { (KLitarg } \\
\text { Bak) }\end{array}$ & $\begin{array}{l}\text { 66,66) } \\
\text { (Cukup } \\
\text { Baik) }\end{array}$ \\
\hline 4 & Mr.D & $\begin{array}{l}\text { 66,66 } \\
\text { [Cukup } \\
\text { Bak) }\end{array}$ & $\begin{array}{l}100 \\
\{\text { Raik\} }\end{array}$ & $\begin{array}{l}75 \\
(\text { Cukup } \\
\text { Baik) }\end{array}$ & $\begin{array}{l}\text { BO } \\
\text { (Cukup } \\
\text { Bakj) }\end{array}$ & $\begin{array}{l}50 \\
\text { \{Kurarg } \\
\text { Bak) }\end{array}$ & $\begin{array}{l}39,33 \\
\text { (Tidak } \\
\text { Eak) }\end{array}$ \\
\hline 5 & Mr.E & $\begin{array}{l}100 \\
(8 \mathrm{ak})\end{array}$ & $\begin{array}{l}100 \\
\text { (Baik) }\end{array}$ & $\begin{array}{l}75 \\
\text { (Cukup } \\
\text { Baik) }\end{array}$ & $\begin{array}{l}\text { a0 } \\
(8 \mathrm{aik}) \text { : }\end{array}$ & $\begin{array}{l}50 \\
\text { (Kurafg } \\
\text { Bak) }\end{array}$ & $\begin{array}{l}\text { 68,66 } \\
\text { (Cukup } \\
\text { Bak) }\end{array}$ \\
\hline 6 & Mr.F & $\begin{array}{l}33,39 \\
\text { (Ticak } \\
\text { Bak) }\end{array}$ & $\begin{array}{l}100 \\
\{\text { Baik\} }\end{array}$ & $\begin{array}{l}75 \\
\text { (Cukup } \\
\text { Baik) }\end{array}$ & $\begin{array}{l}0 \\
\text { (Ticak } \\
\text { Bak] }\end{array}$ & $\begin{array}{l}25 \\
\text { (Tidak } \\
\text { Baik) }\end{array}$ & $\begin{array}{l}0 \\
\text { (Tidak } \\
\text { Eaik) }\end{array}$ \\
\hline
\end{tabular}

Berdasarkan tabel di atas, kondisi bangunan dari 6 pedagang sate kambing dalam kategori tidak baik yaitu kokoh tetapi tidak rapat serangga dan tikus. Lantai di semua pedagang berkategori baik yaitu bersih, kedap air, tidak licin, rata, kering, konus. Dinding di semua pedagang berkategori baik yaitu kedap air, rata, bersih. Ventilasi di semua pedagang berkategori baik yaitu tersedia, berfungsi baik, menghilangkan bau tak enak, cukup menjamin rasa aman. Pencahayaan di semua pedagang berkategori baik yaitu tersebar rata di setiap ruangan, tidak menyilaukan. Atap di semua pedagang berkategori baik yaitu tidak menjadi sarang tikus dan serangga, tidak bocor, bersih. Langitlangit di semua pedagang berkategori baik yaitu tinggi minimal 2,5 meter, rata, bersih, tidak terdapat lubang-lubang. Pintu yang berkategori baik ditemukan pada Mr.A dan Mr. E yaitu rapat serangga dan tikus, menutup dengan baik, terbuat dari bahan yang kuat. Kategori cukup baik ditemukan pada Mr.B, Mr.C, dan Mr.D yaitu rapat serangga dan tikus, tidak menutup dengan baik, terbuat dari bahan yang kuat. Kategori tidak baik ditemukan pada Mr.F yaitu rapat serangga dan tikus, tidak menutup dengan baik, tidak terbuat dari bahan yang kuat. Air bersih di semua pedagang berkategori baik yaitu jumlah mencukupi, tidak berbau, tidak berasa, tidak berwarna. Pembuangan air limbah di semua pedagang berkategori cukup baik yaitu air limbah mengalir dengan lancar, tidak terdapat grease trap, saluran kedap air, saluran tertutup. Toilet berkategori baik ditemukan pada Mr.C dan Mr.E yaitu bersih, letaknya tidak berhubungan langsung dengan dapur atau ruang makan, tersedia air bersih, tersedia sabun, tetapi toilet wanita dan pria tidak terpisah. Kategori cukup baik ditemukan pada Mr.B dan Mr.D yaitu bersih, letaknya tidak berhubungan langsung dengan dapur atau ruang makan, tersedia air bersih, tidak tersedia sabun, toilet wanita dan pria tidak terpisah. Kategori tidak baik ditemukan pada Mr.A dan Mr.F karena belum memiliki toilet. Tempat sampah berkategori kurang baik ditemukan pada Mr.A, Mr.B, Mr.C, Mr.D dan Mr.E yaitu kedap air, tidak tertutup, tidak dilapisi plastik, diangkut setiap 24 jam. Kategori tidak baik ditemukan pada Mr.F yaitu tidak kedap air, tidak tertutup, tidak dilapisi plastik, diangkut setiap24 jam. Tempat cuci tangan dengan kategori baik hanya ditemukan pada Mr.B yaitu tersedia air cuci tangan yang mencukupi, tersedia sabun, tersedia lap. Kategori cukup baik ditemukan pada Mr.C dan Mr.E yaitu air cuci tangan yang mencukupi, tersedia sabun, tidak tersedia lap. Kategori tidak baik ditemukan pada Mr.D yaitu air cuci tangan yang mencukupi, tidak tersedia sabun, tidak tersedia lap. Sementara di tempat Mr.A dan Mr.F belum memiliki tempat cuci tangan.

\section{Enam Prinsip Hygiene Sanitasi Makanan}

1. Pemilihan Bahan Makanan

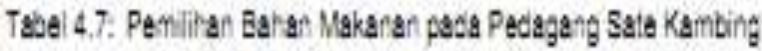
yang Diua di Kesamaian Bumi gyuKabupg:en Brebes Tahun 2014

\begin{tabular}{|c|c|c|}
\hline No & Nama & Pamillhen Bahan Makshan (\%g \\
\hline 1 & Mt:A & 100 (Baik) \\
\hline 2 & Mr. & 100 (Baik) \\
\hline 3 & MrC & 100 (Baik) \\
\hline 4 & Mr.D & 100 (Baik) \\
\hline 5 & Mr.E & 100 (Baik) \\
\hline 6 & Me.F & 100 (Baik) \\
\hline & . $8: 9$ & 100 (Bgik) \\
\hline
\end{tabular}


Dari 6 pedagang sate kambing di Kecamatan Bumiayu Kabupaten Brebes memperoleh daging kambing dari RPH. Pemilihan bahan dari semua pedagang sudah dalam kategori baik yaitu daging kambing beraroma khas, tidak berlendir dan tidak berubah warna.

2. Penyimpanan Bahan Makanan

Tesel 4.8. Patyimpanan Earan Makanan pasa Pecagan't Sate

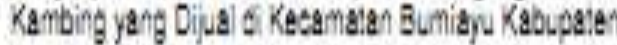
Erabes Tahut 2014

\begin{tabular}{|c|c|c|}
\hline No & Nama & $\begin{array}{l}\text { Penyimpanth Bathan Makanth } \\
(\%)\end{array}$ \\
\hline 1 & Mt:A & 6A,BB (Clkud Bak) \\
\hline 2 & Mr. 8 & 66.66 Clkup Bak? \\
\hline 3 & M:C & BB, BB (Cukup Bak) \\
\hline 4 & $M r .0$ & 68.6B (CLkup Esk) \\
\hline 5 & Mr.E & 68, 68 (Cukup Bak) \\
\hline$B$ & $\mathrm{Mr}, \mathrm{F}$ & 68.68 (Cukup agk) \\
\hline \multicolumn{2}{|c|}{ Rats } & B B, Cakud Bgk) \\
\hline
\end{tabular}

Semua pedagang sate kambing di Kecamatan Bumiayu Kabupaten Brebes menyimpan bahan makanan di wadah yang terbuat dari plastik maupun stainless. Penyimpanan bahan makanan dari semua pedagang sudah dalam kategori cukup baik yaitu tempat penyimpanan bersih, Ketebalan bahan padat tidak lebih dari $10 \mathrm{~cm}$, tetapi belum menyimpan bahan makanan ke dalam lemari es.

3. Pengolahan Makanan

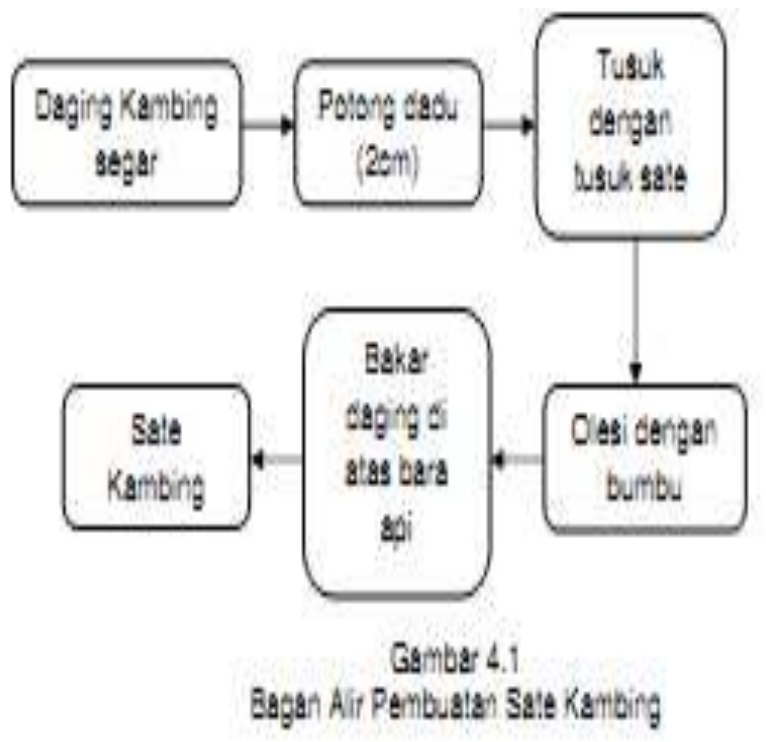

Ada 4 aspek yang menyangkut pengolahan makanan agar makanan yang disajikan sehat, yaitu penjamah makanan, pengolahan makanan, tempat pengolahan dan peralatan masak. Dari 6 pedagang sate kambing tidak ada yang menggunakan APD seperti celemek, sarung tangan, masker, dan penutup kepala pada saat mengolah makanan.

Peralatan yang digunakan dalam pengolahan sate kambing sebagian besar berbahan plastik / melamin dan stainless. Peralatan tersebut memenuhi syarat yaitu baik digunakan karena anti karat, kedap air, mudah dibersihkan dan tidak berbau.

4. Pengangkutan Makanan

Tese 4.10: Pergangutan Makaran paca Pesagarg Say Kambing

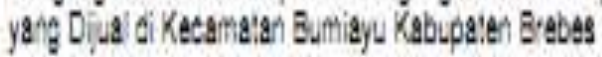
Thlou 2014

\begin{tabular}{|c|c|c|}
\hline No & Nems & Pangengkulan Makanth (\%) \\
\hline$T$ & $\overline{M F \cdot A}$ & 100 (Bak) \\
\hline 2 & Mr.B & $100(\mathrm{Bg} \mathrm{K})$ \\
\hline 3 & MrC & 100 (Bgik) \\
\hline 4 & MtD & 100 (Bak) \\
\hline 5 & Mt:E & 100 (E\&k) \\
\hline 0 & Mt.F & $100(a, k)$ \\
\hline & 189 & $100(38 k)$ \\
\hline
\end{tabular}

Sate kambing yang sudah jadi pada masing-masing pedagang langsung diberikan kepada konsumen. Kategori pengangkutan makanan pada semua pedagang sate kambing adalah baik, yaitu alat / tempat pengangkutan bersih dan jalur pengangkutan mengambil jalan yang singkat, pendek dan terdekat.

5. Penyimpanan Makanan

Sate kambing yang sudah dibakar akan langsung disajikan ke konsumen, jadi tidak ada tempat untuk menyimpan sate kambing.

6. Penyajian Makanan

Tesei 4.11: Peryajan Makanar pasa Pecagang Sate Kanbing yang Diua Gi Kecamaran Bumliayu Kabupa:en Brebes Tghun 2014

\begin{tabular}{|c|c|c|}
\hline No & Nama & Penyal isn Makanth (\%) \\
\hline 1 & Mr.A & 100 (B8ik) \\
\hline 2 & Mr. $\bar{B}$ & 100 [Bak] \\
\hline 3 & MeC & $100(E 8 \mathrm{k})$ \\
\hline 4 & MrD & 100 (Eak) \\
\hline 5 & Mr.E & $100(6 a x)$ \\
\hline 6 & Mr.F & 100 [Esik \\
\hline & - 89 & 100 [eak] \\
\hline
\end{tabular}


Penyajian makanan yang dilakukan oleh 6 pedagang sate kambing di Kecamatan Bumiayu Kabupaten Brebes termasuk dalam kategori baik yaitu menggunakan peralatan makan yang bersih, tidak menggunakan kertas minyak bekas dan plastic yang digunakan tidak terbuat dari bahan yang berbahaya.

\section{Hasil Pemeriksaan Sampel}

Pemeriksaan sampel sate kambing yang dilakukan pada tanggal 9 Juni 2014 di Laboratorium JKL Purwokerto didapatkan hasil bahwa 2 sampel negatif (tidak ada Salmonella) dan 4 sampel positif mengandung Salmonella. Berikut hasil pemeriksaan secara kualitatif di laboratorium:

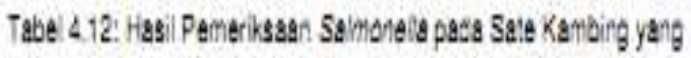

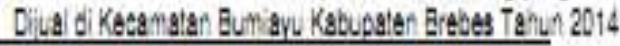

\begin{tabular}{|c|c|c|c|}
\hline No. & $\begin{array}{l}\text { Kode } \\
\text { Sampet }\end{array}$ & $\begin{array}{l}\text { Hesil Pemerikstan pat } \\
\text { gtam/ }\end{array}$ & $\begin{array}{c}\text { Slantar' Ptit } \\
\mathrm{gram} / \mathrm{ml}\end{array}$ \\
\hline 1. & $A$ & Postl (4) & \\
\hline 2 & 8 & Negabi (.) & \\
\hline 3. & C & Negasi (.) & \\
\hline 4. & 0 & Postil (a) & \\
\hline 5. & $E$ & PoS:I (*) & \\
\hline 6. & $F$ & Postil 4 & \\
\hline
\end{tabular}

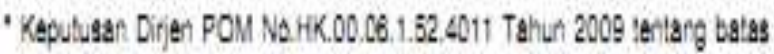

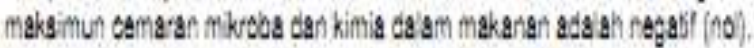

\section{PEMBAHASAN}

\section{A. Gambaran Umum}

Kecamatan Bumiayu merupakan bagian dari Kabupaten Brebes tepatnya di Brebes Selatan. Jumlah pedagang sate kambing di Kecamatan Bumiayu Kabupaten Brebes yaitu 6 pedagang yang menetap.

Berdasarkan tabel 4.1, pengambilan sampel sate kambing dilakukan pada tanggal 9 Juni 2014. Sampel yang diambil dari masing-masing pedagang adalah 3 tusuk sate kambing yang setengah matang. Pendidikan penjual sate kambing rata-rata berpendidikan SMA, hanya Mr.F yang berpendidikan SMP. Di tempat penjualan Mr.A, Mr.B, Mr.F ada 2 penjamah sedangkan di tempat penjualan Mr.C, Mr.D dan Mr.E ada 3 penjamah makanan.

\section{B. Upaya Hygiene Pengolahan Sate Kambing \\ 1. Penjamah \\ Dari 6 pedagang sate kambing yang ada di Kecamatan Bumiayu Kabupaten}

Brebes, penjamah pada Mr.A, Mr.B dan Mr.F ada 2 penjamah sedangkan pada Mr.C, Mr.D, dan Mr.E ada 3 penjamah. Penjamah dari 6 pedagang sate kambing belum pernah mendapatkan penyuluhan tentang sanitasi makanan, tidak memiliki surat keterangan sehat dari dokter, tidak memiliki riwayat penyakit kulit. Personal hygiene dengan kategori baik ditemukan pada Mr.B dan Mr.F yaitu pakaian bersih, kuku pendek, rambut bersih, memakai celemek, tidak menggunakan sarung tangan. Kategori cukup baik ditemukan pada Mr.A dan Mr.C yaitu pakaian bersih, kuku pendek, rambut bersih, tidak menggunakan celemek dan sarung tangan. Sedangkan kategori kurang baik ditemukan pada Mr.D dan Mr.E yaitu pakaian bersih, kuku panjang, rambut bersih, tidak memakai celemek dan tidak menggunakan sarung tangan saat mengolah makanan.

Perilaku penjamah makanan pada 6 pedagang sate kambing di Kecamatan Bumiayu Kabupaten Brebes sudah baik karena tidak merokok saat mengolah makanan, tidak mengobrol, selalu menutup mulut pada waktu bersin, tidak menggaruk-garuk aggota badan saat mengolah makanan, mencuci tangan sebelum dan setelah mengolah makanan. Namun masih ada penjamah yang mengobrol pada saat menggolah makanan, yaitu pada penjamah Mr.A, Mr.C dan Mr.F. (Anwar, Soedarso, dkk.1987, h.53)

2. Alat / Peralatan

Berdasarkan tabel 4.3 dapat dilihat bahwa alat / peralatan pengolahan dari semua pedagang sate kambing yang ada di Kecamatan Bumiayu Kabupaten Brebes termasuk dalam kategori baik yaitu anti karat, kedap air, mudah dibersihkan dan tidak berbau. Prinsip dasar persyaratan perlengkapan / pengolahan makanan adalah aman sebagai alat / perlengkapan pemrosesan makanan. Menurut Anwar, dkk (1989, h.59-61) syarat perlengkapan adalah :

a. Persyaratan umum, bahan harus anti karat, kedap air, halus, mudah dibersihkan, tidak berbau, tidak mudah berubah warna dan tidak berasa.

b. Bila digunakan sambungan, gunakan bahan anti karat dan aman.

c. Bila digunakan kayu sebagai bahan, maka dianjurkan tidak dipakai sebagai 
bahan yang langsung kontak dengan makanan.

d. Bila digunakan plastik, dianjurkan yang aman dan mudah dibersihkan.

3. Bahan

Berdasarkan tabel 4.4 bahwa semua bahan yang ada di 6 penjual sate kambing dalam kategori baik yaitu daging kambing beraroma khas, tidak berlendir dan tidak berubah warna.

4. Tempat Pengolahan

a. Bangunan

Kondisi bangunan dari 6 pedagang sate kambing dalam kategori tidak baik yaitu kokoh tetapi tidak rapat serangga dan tikus.

b. Lantai

Hasil observasi yang dilakukan pada pedagang sate kambing di Kecamatan Bumiayu Kabupaten Brebes, menyebutkan bahwa lantai di semua pedagang berkategori baik yaitu bersih, kedap air, tidak licin, rata, kering, konus. Kondisi tersebut sudah termasuk memenuhi syarat seperti yang disebutkan oleh Depkes RI (1996, h. 10).

c. Dinding

Dinding di semua pedagang sudah memenuhi syarat menurut Anwar, Soedarso, dkk (1987, h. 55) yaitu kedap air, rata, bersih.

d. Ventilasi

Luas ventilasi yang dimiliki 6 pedagang sate kambing di Kecamatan Bumiayu Kabupaten Brebes sudah memenuhi persyaratan yaitu tersedia, berfungsi baik, menghilangkan bau tak enak, cukup menjamin rasa aman.

e. Pencahayaan

Pencahayaan di semua pedagang sudah memenuhi syarat yaitu tersebar rata di setiap ruangan dan tidak menyilaukan.

f. Atap

Atap yang dimiliki oleh semua pedagang sate kambing sudah memenuhi syarat yang disebutkan oleh Anwar, Soedarso, dkk (1987, h.55) yaitu tidak menjadi sarang tikus dan serangga, tidak bocor, bersih.

g. Langit-langit

Langit-langit di semua pedagang berkategori baik yaitu tinggi minimal 2,5 meter, rata, bersih, tidak terdapat lubang-lubang. h. Pintu

Pintu yang memenuhi syarat ditemukan di tempat Mr.A, Mr.B, Mr.C, Mr.D dan Mr.E yaitu rapat serangga dan tikus, menutup dengan baik, terbuat dari bahan yang kuat. Sedangkan di tempat Mr.F belum memenuhi syarat yaitu rapat serangga dan tikus, tidak menutup dengan baik, tidak terbuat dari bahan yang kuat.

i. Air bersih

Air bersih yang tersedia di 6 pedagang sate kambing sudah memenuhi syarat yaitu mencukupi, tidak berbau, tidak berasa dan tidak berwarna.

j. Pembuangan Air Limbah

Pembuangan air limbah di 6 pedagang sate kambing sudah memenuhi syarat menurut Chandra, Budiman (2007, h. 179) yaitu air limbah mengalir dengan lancar saluran kedap air, saluran tertutup k.

k. Toilet

Toilet yang memenuhi syarat ditemukan di tempat Mr, Mr.C, Mr.D dan Mr.E yaitu bersih, letaknya tidak berhubungan langsung dengan dapur atau ruang makan, tersedia air bersih, tersedia sabun, tetapi toilet wanita dan pria tidak terpisah. Sedangkan di tempat Mr.A dan Mr.F belum memiliki toilet.

I. Tempat Sampah

Semua pedagang sate kambing yaitu Mr.A, Mr.B, Mr.C, Mr.D, Mr.E dan Mr.F tidak memenuhi syarat. Hal tersebut dapat menimbulkan adanya vektor pengganggu seperti lalat. Sebaiknya tempat sampah yang memenuhi syarat menurut Anwar, Soedarso, dkk (1987, h.55) yaitu harus kedap air, tertutup dan dilapisi plastik.

m. Tempat Cuci Tangan

Tempat cuci tangan yang memenuhi syarat ditemukan di tempat Mr.B, Mr.C dan Mr.E. Di tempat Mr.D belum memenuhi syarat, sedangkan di tempat Mr.A dan Mr.F belum memiliki tempat cuci tangan.

\section{Enam Prinsip Hygiene Sanitasi Makanan}

1. Pemilihan Bahan Makanan

Dari 6 pedagang sate kambing di Kecamatan Bumiayu Kabupaten Brebes memperoleh daging kambing dari $\mathrm{RPH}$. 
Pemilihan bahan dari semua pedagang sudah dalam kondisi baik.

a. Ciri-ciri daging ternak segar:

1) Tampak mengkilap, warna cerah dan tidak pucat.

2) Tidak tercium bau asam atau busuk

3) Sifat elastis artinya bila ditekan dengan jari akan segera kembali (kenyal) atau tidak kaku.

4) Bila dipegang tidak lekat/lengket tetapi terasa basah.

b. Ciri-ciri daging kambing segar

1) Warna merah jambu

2) Serat halus

3) Lemak keras dan berwarna putih

4) Berbau khas (prengus)

2. Penyimpanan Bahan Makanan

Penyimpanan daging kambing segar di 6 pedagang sate kambing tidak memenuhi syarat, karena daging kambing tidak disimpan di lemari es. Hal tersebut belum sesuai dengan tahap penyimpanan daging menurut Anwar, dkk (h.49-50) tentang syarat penyimpanan daging $\leq 3$ hari adalah $5^{\circ} \mathrm{C}$ sampai $0^{\circ} \mathrm{C}$, suhu yang digunakan untuk menyimpan daging selama 1 minggu adalah $-10^{\circ} \mathrm{C}$, tempat harus rapat serangga dan tikus.

3. Pengolahan Makanan

Ada 4 aspek yang menyangkut pengolahan makanan agar makanan yang disajikan sehat, yaitu penjamah makanan, pengolahan makanan, tempat pengolahan dan peralatan masak. Dari 6 pedagang sate kambing tidak ada yang menggunakan APD seperti celemek, sarung tangan, masker, dan penutup kepala pada saat mengolah makanan. Hal ini tidak sesuai dengan KepMenkes RI No.942 Menkes/SK/VII/2003 tentang syarat-syarat personal hygiene yang meliputi :

a. Menutup luka (pada luka terbuka seperti bisul/luka lainnya)

b. Memakai APD seperti sarung tangan, celemek dan penutup kepala.

c. Mencuci tangan sebelm dan sesudah mengolah makanan.

d. Tidak sambil merokok.

e. Tidak sambil mengobrol.

Peralatan yang digunakan dalam pengolahan sate kambing sebagian besar berbahan plastik / melamin dan stainless. Peralatan tersebut memenuhi syarat yaitu baik digunakan karena anti karat, kedap air, mudah dibersihkan dan tidak berbau.

4. Pengangkutan Makanan

Sate kambing yang sudah jadi pada masing-masing pedagang langsung diberikan kepada konsumen. Kategori pengangkutan makanan pada semua pedagang sate kambing sudah memenuhi syarat yaitu alat / tempat pengangkutan bersih dan jalur pengangkutan mengambil jalan yang singkat, pendek dan terdekat.

5. Penyimpanan Makanan

Sate kambing yang sudah dibakar akan langsung disajikan ke konsumen, jadi tidak ada tempat untuk menyimpan sate kambing.

6. Penyajian Makanan

Penyajian makanan yang dilakukan oleh 6 pedagang sate kambing di Kecamatan Bumiayu Kabupaten Brebes termasuk dalam kategori baik yaitu menggunakan peralatan makan yang bersih, tidak menggunakan kertas minyak bekas dan plastik yang digunakan tidak terbuat dari bahan yang berbahaya. Menurut Anwar, dkk (1987, h.72) penyajian makanan adalah suatu perlakuan menyiapkan makanan dari tempat pengolahan sampai dijual. Syaratsyarat alat penyajian makanan adalah alat ditempatkan dan disimpan dengan fasilitas pembersih, permukaan alat yang berhubungan langsung dengan makanan hendaknya terlindungi dari pencemaran baik oleh konsumen maupun benda perantara lainnya serta kebersihan alatalat.

\section{Hasil Pemeriksaan Sampel Sate Kambing}

Hasil pemeriksaan pada 6 sate kambing di Kecamatan Bumiayu Kabupaten Brebes disapatkan hasil bahwa 2 sampel negatif (tidak ada Salmonella) yaitu pada pedagang Mr.B dan Mr C sedangkan 4 sampel positif mengandung Salmonella yaitu pada pedagang Mr.A, Mr.D, Mr.E dan Mr.F. Menurut Surat Keputusan Dir Jen POM No.HK.00.06.1.52.4011 Tahun 2009 tentang penetapan batas maksimum cemaran mikroba dan kimia dalam makanan adalah negative (nol). 


\section{SIMPULAN DAN SARAN}

\section{A. Simpulan}

Dari hasil pemeriksaan yang telah dilakukan peneliti pada 6 pedagang sate kambing di Kecamatan Bumiayu Kabupaten Brebes dapat diperoleh simpulan sebagai berikut :

1. Pemilihan Bahan Makanan

Berdasarkan hasil pengamatan yang telah dilakukan menggunakan checklist dan kuesioner dari 6 pedagang sate kambing diperoleh hasil rata-rata 100\% sehingga dapat dikategorikan baik.

2. Penyimpanan Bahan Makanan

Berdasarkan

observasi menggunakan checklist dan kuesioner dari 6 pedagang sate kambing diperoleh hasil rata-rata $66,66 \%$ sehingga dapat dikategorikan cukup baik.

3. Pengolahan Makanan

Proses pengolahan dari 6 pedagang sate kambing sudah cukup baik dengan hasil rata-rata $73,6 \%$, hanya saja 6 penjamah belum memakai APD yang lengkap saat mengolah makanan.

4. Pengangkutan Makanan

Berdasarkan observasi dengan menggunakan checklist dan kuesioner, pengangkutan makanan di 6 pedagang sate kambing sudah baik dengan hasil rata-rata $100 \%$.

5. Penyimpanan Makanan

Sate kambing yang sudah dibakar akan langsung disajikan ke

konsumen, jadi tidak ada tempat untuk menyimpan sate kambing.

6. Penyajian Makanan

Berdasarkan hasil pengamatan yang telah dilakukan menggunakan checklist dan kuesioner dari 6 pedagang sate kambing diperoleh hasil rata-rata 100\% sehingga dapat dikategorikan baik.

7. Ada tidaknya Salmonella pada sate kambing

Hasil pemeriksaan pada 6 sampel sate kambing yang dijual di Kecamatan Bumiayu Kabupaten Brebes disapatkan hasil bahwa 2 sampel negatif (tidak ada Salmonella) yaitu pada pedagang Mr.B dan Mr C sedangkan 4 sampel positif mengandung Salmonella yaitu pada pedagang Mr.A, Mr.D, Mr.E dan Mr.F.

\section{B. Saran}

1. Kepada Dinas Kesehatan Kabupaten Brebes sebagai masukan dalam pelaksanaan promosi kesehatan terhadap pedagang makanan khususnya pedagang sate kambing terkait dengan bahaya makanan yang setengah matang.

2. Kepada pedagang sate kambing sebaiknya menyimpan daging kambing segar di lemari es, menggunakan APD yang lengkap seperti celemek dan penutup kepala saat mengolah makanan dan membakar sate kambing sampai benar-benar matang.

3. Kepada konsumen sebaiknya memesan sate kambing yang matang, karena pada sate kambing yang setengah matang masih terdapat bakteri Salmonella $s p$ yang menyebabkan penyakit, misalnya thypus.

\section{DAFTAR PUSTAKA}

Anggun Bangkit Hutami, 2012, Studi Salmonella Pada Ayam Goreng Tepung Pada Pedagang Di Kecamatan Purwokerto Timur Kabupaten Banyumas Tahun 2012, Karya Tulis Ilmiah, Purwokerto: Kementrian Kesehatan RI

Politeknik Kesehatan Semarang Jurusan Kesehatan Lingkungan Purwokerto.

Anwar, Soedarso, dkk, 1987, Sanitasi Makanan dan Minuman pada Institusi Pendidikan Tenaga Sanitasi, Jakarta: Departemen Kesehatan Republik Indonesia.

Arisman, 2009, Keracunan Makanan:Buku Ajar IImu Gizi, Jakarta: EGC Budiman Chandra, 2007, Pengantar Kesehatan Lingkungan, Jakarta: Penerbit Buku Kedokteran EGC

2011, IImu Kedokteran Pencegahan \& Komunitas, Jakarta: Penerbit Buku Kedokteran EGC Depkes RI, 2003, Keputusan Menteri Kesehatan Republik Indonesia Nomor 1098/MENKES/SK/VII/2003 Tentang Persyaratan Hygiene Sanitasi Rumah Makan dan Restoran

2003, Keputusan Menteri Kesehatan Republik Indonesia Nomor 942/MENKES/SK/VII/2003 Tentang Pedoman Persyaratan Hygiene Sanitasi Makanan Jajanan 
2009, Rencana Pembangunan Jangka Panjang Bidang Kesehatan 20052025, Jakarta: Depkes RI

Dirjen PP \& PL KEMENTERIAN KESEHATAN RI, 2010, Kumpulan Modul Kursus Hygiene Sanitasi Makanan \& Minuman, Jakarta: Depkes RI

http://id.wikipedia.org/wiki/Sate diakses pada tanggal 24 Januari 2014, pukul 06:27 http://putraprabu.wordpress.com/2009/01/ 05pengolahmakanan diakses pada tanggal 29 januari 2014, pukul 21:47

http://majalahkesehatan.com diakses pada tanggal 29 Januari 2014, pukul 21:47

http://keslingmks.wordpress.com/2008/12/26/ma kalah-tentang-kasus-keracunan-makanan/ diakses pada tanggal 30 Januari 2014, pukul 06:52

http://m.okezone.com/read/2013/11/03/521/8912 19/korban-keracunan-sate-gulemencapai-104-orang diakses pada tanggal 5 Februari 2014, pukul 11:57

http://regional.kompas.com/read/2012/12/13/085 05129/mediasiber.html diakses pada tanggal 5 Februari 2014, pukul $12: 27$ http://www.tempatonlineku.com/2012/10/resepcara-membuat-sate-kambingempuk.html?m=1 diakses pada tanggal 5 Februari 2014, pukul 13:51

K. A. Buckle, dkk, 2007, Ilmu Pangan, Jakarta: Penerbit Universitas Indonesia (Ul-Press)

Koes Irianto, 2006, Mikrobiologi Menguak Dunia Mikroorganisme Jilid 2, Bandung: Yrama Widya

Mukono, 2006, Prinsip Dasar Kesehatan Lingkungan, Surabaya: Airlangga University Press

Nurwanto dan Abas siregar, 1997, Mikrobiologi Pangan Hewan dan Nabati, Yogyakarta: Kanisus

Retno Widyati, dkk, 2002, Hygiene dan Sanitasi Umum dan Perhotelan, Jakarta: Gramedia Widiasarana Indonesia

Suharsimi Arikunto, 1998, Prosedur Penelitian Suatu Pendekatan Praktek, Jakarta: Rineka Cipta

Tri Cahyono, 2014, Pedoman Penulisan Proposal dan Karya Tulis IImiah/Skripsi (Edisi Revisi Ketiga, Purwokerto: Kementrian Kesehatan RI Politeknik Kesehatan Depkes Semarang Jurusan Kesehatan Lingkungan. 